\title{
A STUDY OF MANAGEMENT OF PTOSIS BY FRONTALIS SUSPENSION
}

\author{
Deepshikha Solanki¹, S. S. Kubrey², Sanchit Gupta ${ }^{3}$
}

\section{HOW TO CITE THIS ARTICLE:}

Deepshikha Solanki, S. S. Kubrey, Sanchit Gupta. "A Study of Management of Ptosis by Frontalis Suspension". Journal of Evolution of Medical and Dental Sciences 2015; Vol. 4, Issue 44, June 01; Page: 7635-7642, DOI: $10.14260 /$ jemds/2015/1108

ABSTRACT: AIM: Management of ptosis by frontalis sling procedure. PURPOSE: To study cosmetic and functional outcome by frontalis sling procedure. METHOD: This is a Retrospective interventional case series studied in RIO Bhopal during academic session of January 2012 to December 2013 in which 18 patients with severe Ptosis with poor levator function attending OPD were evaluated. All cases in our study were of congenital ptosis $(100 \%)$ with poor levator function $(<4 \mathrm{~mm})$. Amount of ptosis determined with Ptosis workup. Phenylephrine test was carried out in all patients to test the function of Muller muscles. Polypropylene suture and silicone rod were used in $50 \%$ cases each; similarly single triangle and pentagon technique done in 50\% cases each. All surgeries were done with eyelid crease incision, Post-operative outcome assessed in terms of palpebral fissure height (PFH), marginal reflex distance (MRD), visual acuity and lid Margin contour. Follow up was done after one month and 3months of surgery. RESULT: Surgical outcome-88.89\% cases improved up to expected correction; under correction in $11.11 \%$ cases. On 3 month follow up lagophthalmos seen in $22.22 \%$ cases, lid crease abnormality in $16.66 \%$, and recurrence in $11.11 \%$ suture exposure in $5.55 \%$ cases. Cosmetic outcome- excellent cosmesis observed in $22.22 \%$ cases, followed by good cosmetic outcome in $66.67 \%$ cases with $11.11 \%$ cases with poor cosmetic outcome. Silicon rod and pentagon technique have better outcome. CONCLUSION: In our study we observed that silicon rod found to have better mean ptosis correction and low rate of complications than polypropylene suture. Pentagon technique has better functional and cosmetic outcome than single triangle. Most of the patients were satisfied with the functional and cosmetic result of the surgery.

KEYWORDS: Bleparoptosis, Blepharoplasty.

INTRODUCTION: Prevalence of congenital ptosis in children is 1 in 842 births. ${ }^{1}$ Equal incidence is seen in men and women. Most common feature of ptosis is drooping of the upper eyelid of the affected eye. Depending on the severity of drooping, it is categorized into- Minimal (1-2mm), Moderate $(3-4 \mathrm{~mm})$, Severe $(>4 \mathrm{~mm}) .^{2}$ Complete physical examination is needed to investigate any associated causes. In severe Ptosis Surgical modalities include correction of eyelid muscle and procedures like levator resection, Muller muscle resection and frontalis sling operation are generally performed. Frontalis suspension is a commonly used surgery in moderate to severe ptosis with poor levator function. ${ }^{3}$ Surgery connects the eyelid to the brow with a sling material and utilizes the power of the frontalis muscle to elevate the poorly functioning eyelid. 4

\section{Indications of frontalis suspension surgery ${ }^{5}$}

- Severe ptosis $(>4 \mathrm{~mm})$ with very poor levator function $(<4 \mathrm{~mm})$.

- Marcus Gunn jaw winking phenomenon.

- Ptosis associated with aberrant regeneration of $3^{\text {rd }}$ nerve.

Present study done at regional institute of ophthalmology Gandhi Medical College Bhopal during the academic session from December 2011 to December 2013. 
MATERIALS AND METHODS: Ptosis, from the Greek "to fall". ${ }^{6}$ Ptosis refers two abnormal drooping of the upper eyelid which can affect one or both the eyes. Frontalis suspension is a commonly used surgery in moderate to severe ptosis with poor levator function. The purpose of this study is to study cosmetic and functional outcome by frontalis sling procedure in ptosis surgery.

The protocol was approved by local ethical committee and informed consent was taken by each patient. Study was done in 14 male patients and 4 female patients of 0-20 yrs. age with poor levator function in all cases. Routine blood and urine investigations were done. Polypropylene sutures were used in 50\% cases and silicon rods were used in remaining 50\% cases. Single triangle and pentagon techniques were used in $50 \%$ each of cases. All surgeries were done with eyelid crease incision. Postoperative outcome was assessed in terms of PFH, MRD, visual acuity and lid margin contour.

\section{OBJECTIVES:}

1. To study cosmetic and functional outcome by frontalis sling procedure.

2. To study long term result of the procedure.

\section{Inclusion Criteria:}

- Severe ptosis with poor levator function.

- Ptosis due to third cranial nerve palsy.

- Ptosis with Marcus Gunn jaw winking phenomenon.

- Bells phenomenon present.

- Physician fitness for surgery and ruling out associated systemic disease.

\section{Exclusion Criteria:}

- Good levator function.

- Mild to Moderate Ptosis.

- Bells phenomenon absent.

Detailed history and clinical examination was done.

\section{Ptosis work up: Included:}

1. Palpebral fissure height.

2. Marginal reflex distance (MRD).

3. Levator Function:

a) Berk Method.

b) Assessment in children by anomalous head posture like child throwing his back suggests a poor levator action.

c) Iliff test for infants.

4. Lid crease height.

5. Marginal Limbal Distance.

6. Traction test.

7. Ocular movements.

8. Schirmers test. 


\section{Associated Signs: Included:}

1. Increased innervations.

2. Fatigability by Cogan's test (lid twitch sign).

3. Jaw winking phenomenon.

4. Bell's phenomenon.

5. Phenylephrine test.

Data are presented as mean \pm standard deviation.

\section{RESULTS:}

\begin{tabular}{|c|c|c|}
\hline $\begin{array}{c}\text { Amount of correction } \\
\text { achieved in MRD }\end{array}$ & $\begin{array}{c}\text { Number } \\
\text { of cases }\end{array}$ & $\mathbf{\%}$ \\
\hline $0-2 \mathrm{~mm}$ & 01 & $5.55 \%$ \\
\hline $3-5 \mathrm{~mm}$ & 12 & $66.67 \%$ \\
\hline$>5 \mathrm{~mm}$ & 05 & $27.78 \%$ \\
\hline Total & 18 & $100 \%$ \\
\hline
\end{tabular}

Table 1: Amount of Correction Achieved

Maximum correction found was between $3-5 \mathrm{~mm}$ (66.67\%), followed by $>5 \mathrm{~mm}$ in $27.8 \%$ cases and $<2 \mathrm{~mm}$ in $5.55 \%$ cases.

\begin{tabular}{|c|c|c|c|c|}
\hline \multirow{2}{*}{$\begin{array}{c}\text { Correction } \\
\text { achieved in MRD }\end{array}$} & \multicolumn{2}{|c|}{ Polypropylene suture } & \multicolumn{2}{c|}{ Silicon rod } \\
\cline { 2 - 5 } & No. of patients & $\%$ & No. of patients & $\%$ \\
\hline $1 \mathrm{~mm}$ & 01 & $11.11 \%$ & 00 & $00 \%$ \\
\hline $2 \mathrm{~mm}$ & 00 & $00 \%$ & 00 & $00 \%$ \\
\hline $3 \mathrm{~mm}$ & 01 & $11.11 \%$ & 00 & $00 \%$ \\
\hline $4 \mathrm{~mm}$ & 02 & $22.22 \%$ & 02 & $22.22 \%$ \\
\hline $5 \mathrm{~mm}$ & 03 & $33.34 \%$ & 05 & $55.56 \%$ \\
\hline $6 \mathrm{~mm}$ & 02 & $22.22 \%$ & 01 & $11.11 \%$ \\
\hline $7 \mathrm{~mm}$ & 00 & $00 \%$ & 00 & $00 \%$ \\
\hline $8 \mathrm{~mm}$ & 00 & $00 \%$ & 01 & $11.11 \%$ \\
\hline Total & $\mathbf{0 9}$ & \multicolumn{3}{|l}{} \\
\hline Table 2: Correction Achieved with different Sutures \\
\hline
\end{tabular}

Polypropylene suture- 9 cases done with this suture, the correction achieved in MRD is in the range of $1 \mathrm{~mm}-6 \mathrm{~mm}$, mean correction being $4.33 \pm 1.58 \mathrm{~mm}$ (SD).

\begin{tabular}{|c|c|c|c|c|}
\hline \multirow{2}{*}{$\begin{array}{c}\text { Correction Achieved } \\
\text { in MRD }\end{array}$} & \multicolumn{2}{|c|}{ Single Triangle } & \multicolumn{2}{c|}{ Pentagon } \\
\cline { 2 - 5 } & No. of patients & $\%$ & No. of patients & $\%$ \\
\hline $1 \mathrm{~mm}$ & 01 & $11.11 \%$ & 00 & $00 \%$ \\
\hline $2 \mathrm{~mm}$ & 00 & $00 \%$ & 00 & $00 \%$ \\
\hline $3 \mathrm{~mm}$ & 01 & $11.11 \%$ & 00 & $00 \%$ \\
\hline $4 \mathrm{~mm}$ & 01 & $11.11 \%$ & 03 & $33.33 \%$ \\
\hline $5 \mathrm{~mm}$ & 04 & $44.45 \%$ & 04 & $44.45 \%$ \\
\hline
\end{tabular}


ORIGINAL ARTICLE

\begin{tabular}{|c|c|c|c|c|}
\hline $6 \mathrm{~mm}$ & 02 & $22.22 \%$ & 01 & $11.11 \%$ \\
\hline $7 \mathrm{~mm}$ & 00 & $00 \%$ & 00 & $00 \%$ \\
\hline $8 \mathrm{~mm}$ & 00 & $00 \%$ & 01 & $11.11 \%$ \\
\hline Total & $\mathbf{0 9}$ & \multicolumn{3}{|c|}{} \\
\hline
\end{tabular}

Single Triangle: With this technique correction achieved is in range of $1 \mathrm{~mm}-6 \mathrm{~mm}$, Mean correction being $4.44 \pm 1.58 \mathrm{~mm}(\mathrm{SD})$.

Pentagon: Out of 9 cases done with this technique correction achieved in MRD is in the range of $4 \mathrm{~mm}-8 \mathrm{~mm}$; the mean correction achieved being $5.11 \pm 1.26 \mathrm{~mm}$ (SD).

\begin{tabular}{|l|c|c|c|c|}
\hline \multirow{2}{*}{ Complications } & \multicolumn{2}{|c|}{ Polypropylene } & \multicolumn{2}{c|}{ Silicon rod } \\
\cline { 2 - 5 } & $\begin{array}{c}\text { No. of cases } \\
\text { (out of 9) }\end{array}$ & \% & $\begin{array}{c}\text { No. of cases } \\
\text { (out of 9) }\end{array}$ & $\%$ \\
\hline Under correction & 02 & $22.22 \%$ & 00 & $0 \%$ \\
\hline Lid crease abnormality & 02 & $22.22 \%$ & 01 & $11.11 \%$ \\
\hline Lagophthalmos & 02 & $22.22 \%$ & 04 & $44.44 \%$ \\
\hline Recurrence & 02 & $22.22 \%$ & 01 & $11.11 \%$ \\
\hline Suture exposure & 00 & $0 \%$ & 01 & $11.11 \%$ \\
\hline
\end{tabular}

Table 4: Complications Related to Sutures

Lid crease abnormality seen in $22.22 \%$ cases with polypropylene suture and $11.11 \%$ cases with silicon rod.

Under correction seen in $22.22 \%$ of cases in which polypropylene sutures used, none of the case with silicon rod shows under correction.

Lagophthalmos seen in $22.22 \%$ cases of polypropylene suture, $44.44 \%$ cases silicone rod. Recurrence seen in $22.22 \%$ cases of polypropylene suture and $11.11 \%$ cases of silicon rod.

\begin{tabular}{|c|c|c|c|c|}
\hline \multirow{2}{*}{ Complications } & \multicolumn{2}{|c|}{ Single triangle } & \multicolumn{2}{c|}{ Pentagon } \\
\cline { 2 - 5 } & $\begin{array}{c}\text { No. of cases } \\
\text { (out of 9) }\end{array}$ & $\mathbf{\%}$ & $\begin{array}{c}\text { No. of cases } \\
\text { (out of 9) }\end{array}$ & $\%$ \\
\hline Under correction & 02 & $22.22 \%$ & 00 & $0 \%$ \\
\hline Lid crease abnormality & 02 & $22.22 \%$ & 01 & $11.11 \%$ \\
\hline Lagophthalmos & 03 & $33.33 \%$ & 03 & $33.33 \%$ \\
\hline Recurrence & 02 & $22.22 \%$ & 01 & $11.11 \%$ \\
\hline Suture exposure & 00 & $0 \%$ & 01 & $11.11 \%$ \\
\hline
\end{tabular}

Table 5: Complications Related with Technique

Under correction was found in $22.22 \%$ cases with single triangle technique.

Lid crease abnormality was $22.22 \%$ in single triangle technique, $11.11 \%$ in pentagon technique.

Lagophthalmos was found in $33.33 \%$ cases with each technique.

Recurrence found in $22.22 \%$ cases with single triangle technique, $11.11 \%$ in cases with pentagon technique. 
Suture exposure was seen in $11.11 \%$ cases with pentagon technique, no case with single triangle shows suture exposure.

\begin{tabular}{|c|c|c|}
\hline Outcome & No. of cases & $\mathbf{\%}$ \\
\hline Under correction & 2 & $11.11 \%$ \\
\hline Overcorrection & 00 & $0 \%$ \\
\hline \multicolumn{2}{|r|}{}
\end{tabular}

Table 6: Outcome of Surgery

Out of 18 cases operated expected correction achieved in 88.89\%nwhile 2 case $(11.11 \%)$ show under correction. Overcorrection found in none of the cases.

\begin{tabular}{|c|c|c|c|c|}
\hline \multirow{2}{*}{ Grade } & \multicolumn{2}{|c|}{ Polypropylene } & \multicolumn{2}{c|}{ Silicon rod } \\
\cline { 2 - 5 } & No. of cases & $\mathbf{\%}$ & No. of cases & $\mathbf{\%}$ \\
\hline Grade 0/excellent & 02 & $22.22 \%$ & 02 & $22.22 \%$ \\
\hline Grade 1/good & 05 & $55.56 \%$ & 07 & $77.78 \%$ \\
\hline Grade 2/poor & 02 & $22.22 \%$ & 00 & $00 \%$ \\
\hline
\end{tabular}

Table 7: Cosmetic Outcome with Different Sutures

Polypropylene suture shows grade 0 (excellent) cosmetic outcome in $22.22 \%$ cases, grade 1 (good) outcome in $55.56 \%$ cases and grade 2 (poor) in $22.22 \%$ cases.

Silicon rod has grade 0 (excellent) cosmetic outcome in $22.22 \%$ cases and grade 1 (good) in $77.78 \%$ cases.

\begin{tabular}{|c|c|c|c|c|}
\hline \multirow{2}{*}{ Grade } & \multicolumn{2}{|c|}{ Single triangle } & \multicolumn{2}{c|}{ Pentagon } \\
\cline { 2 - 5 } & No. of cases & $\mathbf{\%}$ & No. of cases & \% \\
\hline Grade 0/excellent & 02 & $22.22 \%$ & 02 & $22.22 \%$ \\
\hline Grade 1/good & 05 & $55.56 \%$ & 07 & $77.78 \%$ \\
\hline Grade 2/poor & 02 & $22.22 \%$ & 00 & $00 \%$ \\
\hline \multicolumn{2}{|c|}{ Table 8: Cosmetic Outcome with Different Technique } \\
\hline
\end{tabular}

Single triangle technique shows grade 0 (excellent) cosmetic outcome in $22.22 \%$ cases, and grade 2 (poor) in $55.56 \%$, and grade 2 (poor) in $22.22 \%$ cases.

Pentagon technique shows grade 0 (excellent) cosmetic outcome in $22.22 \%$ cases, grade 1 (good) in $77.78 \%$ cases.

\begin{tabular}{|c|c|c|}
\hline & No. of cases & $\mathbf{\%}$ \\
\hline Achieved & 16 & $88.89 \%$ \\
\hline Not achieved & 02 & $11.11 \%$ \\
\hline
\end{tabular}

Table 9: Patients Satisfaction Achieved

$\mathrm{Df}=1, \mathrm{p}<0.001$ (Highly significant), non-parametric chi square test applied $88.89 \%$ cases were satisfied with the cosmetic appearance after surgery $11.11 \%$ cases were dissatisfied with cosmetic appearance after surgery, these cases were those having under correction. 
DISCUSSION: This study was done to evaluate the various aspects of management of ptosis by frontalis suspension procedure with reference to various techniques and types of sutures used:

- Frontalis suspension surgery found to be effective procedure in ptosis correction between 3 $5 \mathrm{~mm}$ and $>5 \mathrm{~mm}$, only $5.55 \%$ cases show correction of $<2 \mathrm{~mm}$.

- As regard to correction with sutures silicon rod shows better correction (mean 5.22 \pm 1 . $22 \mathrm{mmSD}$ ) than polypropylene suture (mean $4.33 \pm 1.58 \mathrm{mmSD}$ ). It shows slight difference with the study done by Zulfiquar Ali et al 2011 who found mean change in MRD $\geq 3.5 \mathrm{~mm} .^{7}$ Similarly Morris CL et al 2008 found mean elevation in MRD $\geq 2 \mathrm{~mm} .^{8}$

- As per correction achieved with different techniques pentagon has better correction (mean 5 . $11 \pm 1.26 \mathrm{mmSD}$ ) than single triangle (mean $4.44 \pm 1.58 \mathrm{~mm}$ SD) but Ben Simon GJ et al 2005 in contrast found surgical outcome of both techniques to be similar. ${ }^{9}$

- Lid crease abnormality and recurrence seen more in polypropylene suture $(22.22 \%)$ than silicon rod (11.11\%).

- Under correction seen in $22.22 \%$ cases of polypropylene suture while no case with silicon rod shows under correction. S. Hassan Raza Jafri et al 2013 found under correction in $6.66 \%$ cases with polypropylene suture; high percentage in our study may be due to small sample size.10

- Lagophthalmos is more with silicon rod (44.44\%) than that with polypropylene suture (22.22\%). Similar rate of lagophthalmos was found by S. Hassan Raza Jafri et al 2013 (20\% cases of lagophthalmos with polypropylene sutures)..$^{10}$

- $\quad$ Rate of lagophthalmos is equal in both techniques (33.33\%).

- Under correction seen with single triangle technique (22.22\%).

- Lid crease abnormality and recurrence seen more in single triangle (22.22\%) than in pentagon technique (11.11\%). Recurrence rate with polypropylene suture is high ranging from $12.5 \%$ $55 \%$ as found by Wasserman BN 2001, while chow K et al 2003 found it to be $22 \%$ which is close to our study. ${ }^{11}$

- $\quad$ Recurrence rate with silicon rod is less (11.11\%), it is found to be $7 \%$ in study done by Carter SR et al 1996.12

- $\quad 88.89 \%$ cases improved up to expected correction, under correction in $11.11 \%$; no case shows over correction. These results are similar to study done by Mehta P et al 2009. Who found 73\% final outcome of congenital ptosis correction and Carter SR 1996 who found 100\% expected correction in their study.

- $\quad$ On 3 month follow up lagophthalmos was present in $22.22 \%$ cases, lid crease abnormality in $16.66 \%$, and recurrence in $11.11 \%$ cases.

- Silicon rod has better cosmetic outcome as all cases show excellent (22.22\%) and good (77.78\%) outcome, while polypropylene shows excellent cosmetic outcome inn $22.22 \%$ cases, good outcome in $55.56 \%$ cases and poor outcome in $22.22 \%$ cases. Consistent with S. Hassan Raza Jafri 2013 study.

- Pentagon technique has better outcome as all cases show excellent (22.22\%) to good (77.78\%) outcome, while single triangle shows excellent cosmetic outcome in $(22.22 \%$ good outcome in $55.56 \%$ cases and poor in $22.22 \%$ cases. Ben Simon GJ et al 2005 found that there is no difference in recurrence, function or cosmetic result between these two commonly performed techniques.

- $\quad 88.89 \%$ cases were satisfied with the functional and cosmetic result of surgery. 


\section{CONCLUSION:}

- Silicon rod found to have better mean ptosis correction and low rate of complications than polypropylene suture.

- Pentagon technique has better functional and cosmetic outcome than single triangle.

- Most of the patients were satisfied with the functional and cosmetic result of the surgery.

\section{REFERENCES:}

1. Griepentrong GJ, Diehl NN, Mohney BG, incidence and Demographics of childhood ptosis, Ophthalmology. 2011 Jun; 118(6): 1180-3. Doi; 10. 1016/j. ophtha. 2010. 10. 026. Epub 2011 Apr 15.

2. Kanski clinical ophthalmology, $6^{\text {th }}$ edition, 2007.

3. Anderson RL, Jordan DR, Dutton JJ, Whitnall's sling for poor function ptosis. Arch Ophthalmol. 1990; 108: 1628-32 (pubmed).

4. Beyer CK, Albert DM. the use and fate of fascia lata and sclera in ophthalmic plastic and reconstructive surgery, The 1980 Wendell Hughes lectures. Ophthalmology. 1981: 88: 869-86.

5. Finsterer J. ptosis: causes, presentation, and management. Aesth Plast Surg 2003; 27: 193-133. . ophthal.

6. Older JJ, Dunne PB. Silicone slings for the correction of ptosis associated with progressive external ophthalmoplegia. Ophthalmic Surg 1984; 15: 379-81.

7. Zulfiquar Ali et al $2011 \mathrm{~J}$ Ayub Med Coll Abbottabad 2011; 23(4).

8. Morris CL, Buckley EG, Enyedi LB, Stinnett S, Freedman SF: Safety and efficacy of silicone rod frontalis suspension surgery for childhood ptosis repair. Journal of Paediatric Ophthalmology and Strabismus, 2008; 45(5): 280-288.

9. Ben SGJ, Macedo AA, Schwarcz R M, Wang DY, McCann JD, Goldberg RA: . Frontalis suspension for upper eyelid ptosis; evaluation of different surgical designs and suture material. American Journal of Ophthalmology, 2005; 140(5): 877-885.

10. S. Hassan Raza Jafri, Abdul Rauf, Nazia Qidwai, Abdul Rashid Shaikh, Fayaz Ahmed Soomro, Ashraf Dawood Pak J Ophthalmol 2013, Vol. 29 No. 1.

11. Wasserman BN, Sprunger DT, Helveston EM: Comparision of materials used in frontalis suspension, Archives of Ophthalmology, 2001; 119(5): 687-691.

12. Carter SR, Meecham WJ, Seiff S R: Silicone frontalis slings for the correction of blepharoptosis: indication and efficacy. Ophthalmology, 1996; 103(4): 623-630. 


\section{ORIGINAL ARTICLE}

\section{AUTHORS:}

1. Deepshikha Solanki

2. S. S. Kubrey

3. Sanchit Gupta

\section{PARTICULARS OF CONTRIBUTORS:}

1. Senior Resident, Regional Institute of Ophthalmology, Bhopal.

2. Assistant Professor, , Regional Institute of Ophthalmology, Bhopal.

\section{FINANCIAL OR OTHER} COMPETING INTERESTS: None
3. Junior Resident, Regional Institute of Ophthalmology, Bhopal.

\section{NAME ADDRESS EMAIL ID OF THE} CORRESPONDING AUTHOR:

Dr. Deepshikha Solanki, W/o. Mr. Chandrashekhar Solanki, D-21, char Imli,

Bhopal-462016.

E-mail: drdeeepshikha.eyes@gmail.com

Date of Submission: 08/05/2015. Date of Peer Review: 09/05/2015. Date of Acceptance: 23/05/2015. Date of Publishing: 30/05/2015. 